\title{
SHEEP TICK AND SHEEP MAGGOT PROBLEMS IN GREAT BRITAIN*
}

$\mathrm{T}$ HE sheep tick, Ixodes ricinus L., in the British Isles is confined principally to the uncultivated regions, the hills and moorlands, the wooded districts or areas of peat bog. It is responsible for the transmission of louping ill and tick-borne fever in sheep and for widespread pyæmic infections in young lambs. The losses in sheep stock may be very severe if the flock has not been acclimatized to these diseases. Death-rates of upwards of 50 per cent have been recorded in the first year of exposure to infestation by disease-infected ticks.

The tick can live on a variety of hosts, and experiment has shown that it can survive as a species in the absence of sheep. The physical factors controlling its distribution have been shown to be moisture during the summer and possibly temperature during severe winters. The conditions of high humidity in the summer and protection from black frosts in the winter are only to be found in rough pastures over peaty or acid soils where there is a layer of moss and rank or old vegetation; that is, precisely those vast expanses of wild moorland and hill the reclamation of which is out of the question. The protection of the sheep by chemical means has therefore been the main line of attack.

Over the greater part of Britain the tick has two seasons of activity; it appears in large numbers on sheep in spring and early summer, and to a less extent in the autumn. Provided sheep can be protected during these periods, they may be allowed to graze over infested pastures without precautions during the rest of the year.

Sodium arsenite $(0 \cdot 2$ per cent arsenious oxide) has been shown to continue to kill adult female ticks attaching to sheep for a period of 10-14 days. Derris, at a concentration of 0.02 per cent resin, has a similar effective duration. The addition of wool grease enhances the effective duration of arsenic but not of derris. Based on these findings, a protective dip has been evolved which gives protection of a high order during the first week or ten days, when the ticks are killed by the derris before they can attach. Afterwards the protective effect is due to the arsenic, whicl kills the females after they attach. For this dip an immersion period of at least half a minute is necessary. The dip is suitable for dipping sheep generally, but in particular it is useful for the dipping of lambing flocks. It is advocated that one dip be given immediately prior to lambing and another after about three weeks. For lambs a derris dust is userl; this was suggested by Mr. Lyle Stewart of King's College, Newcastle, and it has been tested out on a large scale by him. It gives satisfactory protection for about a fortnight. The harmlessness of derris (except as a fish poison) makes it a useful substance for frequent dipping of sheep where it is

* An article based on the following papers read at the annual general meeting of the Association of Applied Biologists on February 14, 1941 .

"Recent work on the Sheep Tick and its bearing on control Measures", by Dr. J. McLeod.

"Recent work on the Sheep Maggot problem", by Dr. R. P. Hobson. "Some practical aspects of the Sheep Blowfly Problem", by Dr. I. Thomas. desired to reduce a tick infestation by using sheep as trap animals.

The losses due to sheep maggots can be classed under two main heads: the direct loss of meat caused by death or loss of condition; the indirect loss due to the labour involved in looking for and cleaning up infested or dirty sheep. The chief culprit in Britain is the 'green-bottle', Lucilia sericata Mg., but recent work has shown that other blowflies attack sheep in certain circumstances.

Before maggots can develop on sheep, two conditions are necessary : (1) the fly must be attracted to lay in the fleece; (2) the environment must be suitable for the development of the eggs and larvæ. Various putrefying materials attract $L$. sericata to oviposit on live sheep in the field; also, ammonium carbonate, indole or skatol, all typical products of putrefaction. These materials only attract gravid females of $L$. sericata, and they are only effective in conjunction with live sheep, which supply a second essential factor. The limiting factor for the growth of maggots in the fleece is moisture. At the temperature of the sheep's skin, blow-fly eggs and larvæ cannot survive unless the humidity approaches saturation. The relative humidity of the basal fleece air is normally too low for the establishment of myiasis ; it is below 50 per cent in dry weather and seldom exceeds 70 per cent after rain.

The majority of strikes occur in the tail region, as wool soiled with loose dung or urine supplies the conditions necessary for maggots. However, strike is quite common in clean wool on the back, where moist conditions may be due to penetration of the fleece by rain or excessive secretion by the skin glands. One method of control is the prevention of the development of a susceptible area. 'Crutching' is a simple method of preventing strike in the tail region. This consists of shearing the wool away from the area around the tail so that this part keeps clean. Crutching is an established method in Australia and has given good results in experiments in North Wales; it keeps the sheep clean and free from maggots for about four weeks until the wool grows again. Unfortunately, there is a great deal of prejudice against the method on account of its effect on the appearance of the sheep.

Advances in chemical control have been made possible by this work on susceptibility, repellents being tested by making sheep attractive with indole, larvicides by an experimental method of producing myiasis (by placing eggs or young larvæ under a pad of moist cotton, wool in the fleece). As maggot flies are strongly attracted to sheep, repellents have only a limited value. The fly dips in most general use are ar senical mixtures which act mainly through larvicidal action. For preventing maggots, it is the arsenic close to the skin which is effective, and this soon becomes reduced in amount, not by leaching with rain, but by the growth of new wool. Calomel has recently been found to be a promising material for preventing maggot infestation; it acts against the egg stage, the active principle being apparently mercury vapour. Calomel may be too expensive for 
dipping purposes, but should prove useful as an ingredient of preventive dusts and maggot dressings.

The presence of dung and urine in the dip may seriously impair its protective action. Suint, the water-soluble fraction of the fleece, is a further contaminant which may be more important. Suint contains a large proportion of soap; this dissolves in the dipping fluid and completely changes its physical properties, the surface tension falling appreciably. When much suint has accumulated in the dip, the retention of arsenic by the fleece is reduced and the immunity to artificial maggot infestation is decreased; these observations may explain the poor results often obtained when large numbers of sheep are dipped without changing the bath.

With regard to the treatment of infested sheep, further information is required about the breeding habits of the fly. If the sheep blow-fly population is derived mainly from live sheep, and not from carrion, then the first essential of a good dressing is the killing of maggots. It should also promote rapid healing and protect the wound against re-infestation.

In a problem of this nature there are two main avenues of attack : the host might be made immune or very resistant, or the pest might be greatly reduced or exterminated. Work in Britain has been con- centrated mainly on chemical means of protecting the host by the use of dips. Jetting has been tried in Scotland, but protective dusts have not been experimented with on a large scale. The control measures at present available to the farmer are dipping and crutching. Indirectly, the prevention of scouring in sheep by good shepherding and the use of anthelminthics, is important.

Our knowledge regarding the ecology of the sheep blowfly in Britain lags very much behind the biochemical work on the maggots and the susceptibility of the host. We know practically nothing about sheep blowfly populations or the ecological factors governing them. Perhaps the most pressing need is for knowledge of carrion-infesting flies, in particular the question of competition. Important practical recommendations resulted from such a study in Australia.

This unsatisfactory position is considered to be due to the facts that: (1) the farmer, not realizing how serious are the losses caused by sheep blowfly, has not pressed for control measures ; $(2)$ the subject is not one normally dealt with by either the veterinary investigation officer or the advisory entomologist; (3) money for this ecological work has not been available ; (4) failure adequately to carry the results of present research over to the farmer.

\title{
THE CAMPBELTOWN RAISED BEACH AND ITS CONTAINED STONE INDUSTRY*
}

\author{
By Dr. W. J. McCallien and A. D. Lacaille
}

$\mathrm{T}$ HE flint implements of Campbeltown are well known. The original discovery was made in the deposits of the so-called 25-ft. raised beach by a local naturalist, Alexander Gray, in 1894. The Abbé $H$. Breuil described and discussed them in his classic paper, "The Pre-Neolithic Industries of Scotland" (Proc. Soc. Ant. Scot., 56, 261-81 ; 1921-22).

As many diverging views have since been expressed on these artefacts, excavations were recently undertaken to determine their stratigraphical situation and cultural age, a site in the post-glacial raised beach, some $35 \mathrm{ft}$. above ordnance datum, near the Albyn Distillery, Campbeltown, being selected for exploration. The work yielded 1,235 objects attesting man's attention. Of these 724 were definable artefacts, 559 being of flint (the raw material imported from Ireland), 157 of quartz and 8 of schistose grit. Many are heat-crackled, a feature commonest among the waste which indicates their derivation from an occupation-site. The conditions of discovery are generally similar to those of previous finds in that the artefacts were found distributed throughout the upper part of the beach deposits, although locally they were concentrated.

The components of the Campbeltown stone industries constitute the earliest evidence of the colonization of this part of Scotland. Originating from sites occupied on the shore during the time of rising sealevel in the early post-glacial period, they were incorporated into the beach formation during the emergence which followed.

-Summary of a paper read to the Society of Antiquaries of Scotland on February 22.
The present study now enables us to determine a closer connexion between the industries of the equivalent raised beach on the Scottish and Irish sides of the North Channel. The Upper Palæolithic tradition so often stressed as being strong in the Argyll beach industry is not the only influence which left a mark on the stone products of the settlers. A faint Azilian strain appears in some steep round scrapers, while Tardenoisian influence is manifested by some artefacts, including that significant cultural index the micro-burin. The infiltration of Baltic Forest Culture is also suggested by a few objects, a small pick being particularly significant. On the other hand, some tool-forms, such as the "Larne pick", previously unknown outside Ireland are now seen to have a place in Scotland.

This new Campbeltown series of implements, belonging to what is essentially a fine blade industry, compares strictly with those of the Antrim beach assignable to the Early Atlantic climatic period and to Early Mesolithic culture. The Campbeltown industry is equated with Movius's Horizon 2 (Early Larnian) at Cushendun (Proc. Roy. Irish Acad., 46, c.r., $1-84 ; 1940)$. The Campbeltown group, however, including gravers, micro-burins, trimmed and obliquely truncated flakes abruptly retouched, and a pick, is more comprehensive and advanced cultur. ally than its close counterpart across the North Channel.

The conclusion is reached that $(a)$ from various pre-Neolithic elements the beach people developed a provincial culture of their own, (b) Tardenoisian methods of implement manufacture had reached 